\section{Gategory}

Synthesis of Natural

Products and

Potential Drugs

\section{Key words}

spirotryprostatin A

Mizoroki-Heck reaction

diketopiperazines

spirocycles

\title{
Total Synthesis of Spirotryprostatin A
}

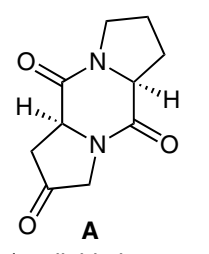

(available in 5 steps and $71 \%$ yield)

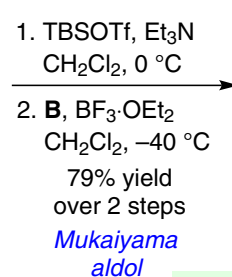<smiles>O=C1C[C@H]2C(=O)N3CCC[C@H]3C(=O)N2/C1=C\CO[Na]</smiles>

$(E: Z 6.6: 1)$ $\underset{50 \% \text { yield }}{\stackrel{6 \text { steps }}{\longrightarrow}}$

$50 \%$ yield<smiles>C/C=C1\C[C@H]2C(=O)N3CCC[C@H]3C(=O)N2[C@H]1CC=O</smiles>

D
Significance: Spirotryprostatin A, a spirocyclic diketopiperazine natural product that was isolated in 1996, was found to be an inhibitor of the mammalian cell cycle in G2/M phase and thus an interesting lead in drug discovery. A number of syntheses of spirotryprostatin A have been disclosed, and Fukuyama now describes a synthetic strategy that relies on a Heck reaction for the elegant installation of the quaternary stereocenter.
Comment: A silyl enol ether derived from diketopiperazine $\mathbf{A}$ underwent a Mukaiyama aldol reaction with aldehyde $\mathbf{B}$ to afford enone $\mathbf{C}$, which was converted into aldehyde $\mathbf{D}$ in six steps. Addition of aryl Grignard E followed by oxidation of the resulting secondary alcohol furnished ketone $\mathbf{F}$, which gave spirocycle $\mathbf{G}$ in the key Heck reaction. The anilide was then introduced through Beckmann rearrangement $(\mathbf{G} \rightarrow \mathbf{H})$. $\mathbf{H}$ could be advanced into the target molecule in five additional steps.

SYNFACTS Contributors: Erick M. Carreira, Simon Krautwald 